\title{
Framework for Conference Management System
}

\author{
Abu Bakar Md Sultan, Abdul Azim Abdul Ghani \& Lim Su Fang \\ Department of Information System \\ Universiti Putra Malaysia \\ 43400 UPM Serdang, Malaysia \\ E-mail: abakar@fsktm.upm.edu.my, azim@fsktm.upm.edu.my
}

This research is sponsored by Research University Grant Scheme RUGS: 05-02-07-0346RU from Universiti Putra
Malaysia

\begin{abstract}
This paper presents a Web-based Conference Management System framework that is intended to support multiple conferences and facilitate the conference management starting from the conference preparation until the attendance tracking process during conference day. The framework derived from the analysis of several web-based related applications. The framework is presents and the results are discussed.
\end{abstract}

Keywords: Conference Management, Web Application, System Framework

\section{Introduction}

Conference is a meeting for researchers to present, discuss, identify important problems and formulate future research direction on specific themes. It provides a true learning environment. However, organizing a conference entails plenty of time-consuming work. For instance, collecting paper submission from authors, assigning paper submitted to the reviewers, notifying authors about whether the paper submitted is rejected or accepted. These processes will surely consume a lot of precious time and complicated works if a conference is conducted manually. Unfortunately, there are no reports from literatures that are seriously looking in how to produce an efficient system in managing the entire process of conferences.

Lately, the need of systems for collaboration support has expanded, leading to their growing application in organizational, communication, and cooperation processes. Hence, various applications have been developed for conference organization to support or manage the workloads. The emergence of information communication technology has changed the way the conferences suppose to organize. Thus this paper analyzes several online conferences and proposes a framework for conference management system.

This paper presents a web-based Conference Management System framework that is intended to support multiple conferences and facilitate the conference management starting from the conference preparation until the attendance tracking process during conference day.

The rest of paper is organized as follows. In section 2 the analysis of features of current system and the solution are discussed. An overview of a proposed solution is discussed in section 3. Section 4 includes the result and discussion. Section 5 includes the conclusion and future suggestion.

\section{Analysis of Existing Conference System}

A Conference Management System shall include functions such as the online participant registration, paper submission, paper reviewing, and notification process and so on. Through the study of the Conference Management System available in the market, we study four most popular solutions for conference system which is ConfMan, CyberChair, Confious and Chairman. The study revealed some differences between the systems. Details of the analysis are listed in the table below:

The result from the Table 1 shows that each product has own advantages and disadvantages. Most of them are still lacking throughout the entire conference management process.

As far as we are concerned, there is no research to produce a common framework for any Conference Management System. Each system only developed when the conference is going to organize. The system developed not only includes the main function of a conference but also to propose a common framework that allows the conference organizer to 
create and customize the conference website. Hence, the main objective of the system is to reduce the effort and in the meantime increase the efficiency and productivity in managing a conference.

\section{Proposed Framework.}

The old fashioned ways in organizing a conference will costs and consume a lot of precious time and effort. For this reason, technical support tools and components are integrated to cope with the problems.

Basically, the system developed consists of three layers, Conference Management Dashboard, Conference Management Platform (operation), and the database layer. There are five stakeholders for the system, namely the system administrator, conference administrator, participant, presenter and reviewer. The Conference Management Dashboard is managed by System Administrator to monitor the performance/status of all registered conference in the portal. The operation of the Conference Management System consists of several modules which are the participant registration, paper management, paper review manager, messaging module.

\subsection{Paper Submission Process}

For the paper submission process, "apache common fileupload" component is used to ease the process. This uploading tool allows the presenters to submit their papers electronically with just a few mouse clicks. Apart from that, the papers uploaded by presenter will be kept in a file directory that facilitate the paper management and reduce the possibility of paper lost. A search engine is built-in in order to reduce the time taken in the searching paper or document process.

\subsection{Notification Process}

Conference Administrator uses the messaging module to notify the presenters about the paper's acceptance decision. Other than that, the messaging module will be integrated with SMS to provide e-mail to short messaging. This SMS function is to ensure that the participants and reviewers are always updated with the conference information.

\subsection{Paper Assignment Process}

Paper assignment is proposed to assign the papers submitted to reviewers.

\subsection{Paper Reviewing Process}

The system developed allows reviewers to download and grade the papers assigned to them. Besides that, multiple files download function also included to assist Conference Administrator in downloading all the papers submitted.

\subsection{Conference Customization}

Content Management System (CMS) is integrated in order to assist the conference organizer to customize the conference website. This CMS allow the conference organizer to manage the creation, modification, and removal of content from a Web site without needing the expertise of a Webmaster.

\section{Result and Discussion}

From the stimulation, paper submission, and paper assigning process can be done within 5 seconds. Other than that, papers or documents are well-managed and errors caused by human are reduced.

\section{Conclusion and Future Suggestion}

The system developed is expected to reduce the cost, effort and time in managing a conference. It also promotes paperless and environment friendly by reducing the paperwork involved in a conference. Our future effort is to propose autonomous Conference Management System with the aims further reducing resources in managing conferences.

\section{References}

http://searchsoa.techtarget.com/sDefinition/0,,sid26_gci508916,00.html

http://www.easychair.org/

http://www.iec.org/online/tutorials/wire_sms/topic04.html

P. Halvorsen, K. Lund, V. Goebel, T. Plagemann, T Preuss \& H. Hartmut, "ConfMan: Integrated WWW and DBS Support for Conference Organization“, Poster Proceedings of The Eighth International World Wide Web Conference (WWW'8), Toronto, Canada, May 1999, pp. $34-35$.

V. Levacic, H. Bogunovic, S. Loncaric, B.Kuzmic, \& B. Blazona: "Chairman: A Confrence Management System ", $28^{\text {th }}$ International Convention MIPRO, Opatija, Croatia, May 30 - June 3, 2005 
Table 1. Comparison of existing Conference Management System

\begin{tabular}{|l|l|l|l|l|}
\hline Function & $\begin{array}{l}\text { ConfMan } \\
{[\mathbf{3}]}\end{array}$ & $\begin{array}{l}\text { CyberChair } \\
{[\mathbf{5}]}\end{array}$ & $\begin{array}{l}\text { Confious } \\
{[\mathbf{1}]}\end{array}$ & Chairman [4] \\
\hline $\begin{array}{l}\text { Participant } \\
\text { Registration }\end{array}$ & $\mathrm{Y}$ & & $\mathrm{Y}$ \\
\hline $\begin{array}{l}\text { Paper } \\
\text { Submission }\end{array}$ & $\mathrm{Y}$ & $\mathrm{Y}$ & $\mathrm{Y}$ & $\mathrm{Y}$ \\
\hline $\begin{array}{l}\text { Paper } \\
\text { Assignment }\end{array}$ & & $\mathrm{Y}$ & $\mathrm{Y}$ & $\mathrm{Y}$ \\
\hline $\begin{array}{l}\text { Bidding } \\
\text { Process }\end{array}$ & $\mathrm{Y}$ & $\mathrm{Y}$ & $\mathrm{Y}$ & \\
\hline $\begin{array}{l}\text { Paper } \\
\text { Downloading }\end{array}$ & $\mathrm{Y}$ & $\mathrm{Y}$ & $\mathrm{Y}$ & $\mathrm{Y}$ \\
\hline $\begin{array}{l}\text { Paper } \\
\text { Reviewing }\end{array}$ & $\mathrm{Y}$ & & $\mathrm{Y}$ & $\mathrm{Y}$ \\
\hline $\begin{array}{l}\text { Notification } \\
\text { Process }\end{array}$ & $\mathrm{Y}$ & & $\mathrm{Y}$ & \\
\hline $\begin{array}{l}\text { Online PC } \\
\text { meeting }\end{array}$ & $\mathrm{Y}$ & & \\
\hline Setup Phase & & & & \\
\hline
\end{tabular}

Table 2. System Framework

\begin{tabular}{|c|c|c|c|c|c|c|c|}
\hline \multicolumn{8}{|c|}{ Conference Management Dashboard } \\
\hline 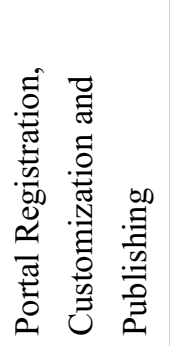 & 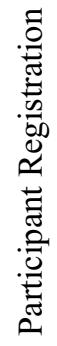 & 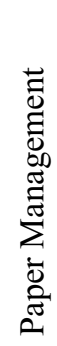 & 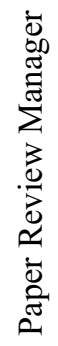 & 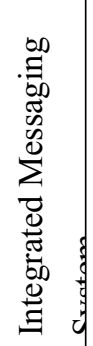 & 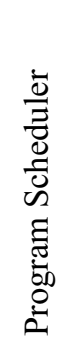 & 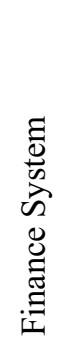 & 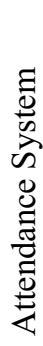 \\
\hline \multicolumn{8}{|c|}{ Centralized Database } \\
\hline
\end{tabular}




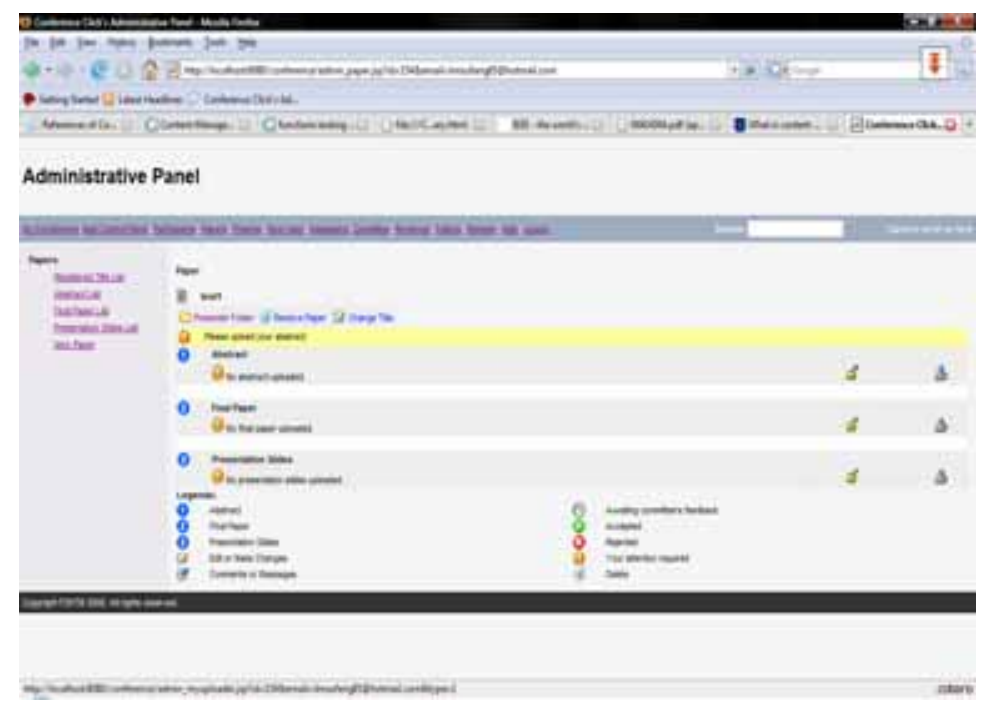

Figure 1. Screen Snapshot of Paper Submission Process

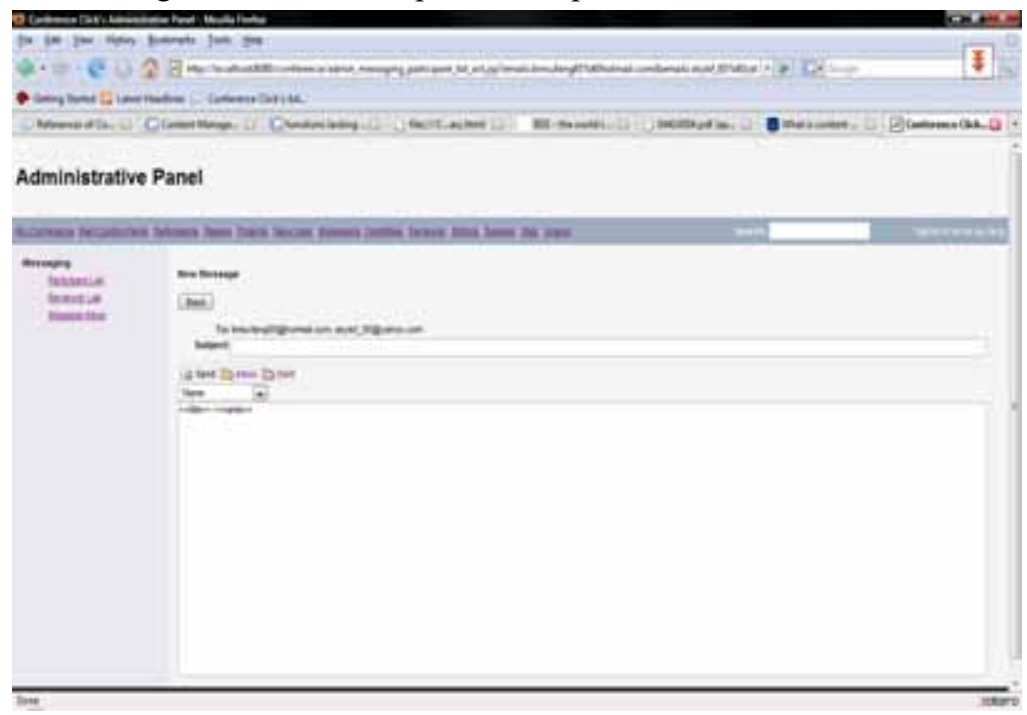

Figure 2. Screen Snapshot Notification Process

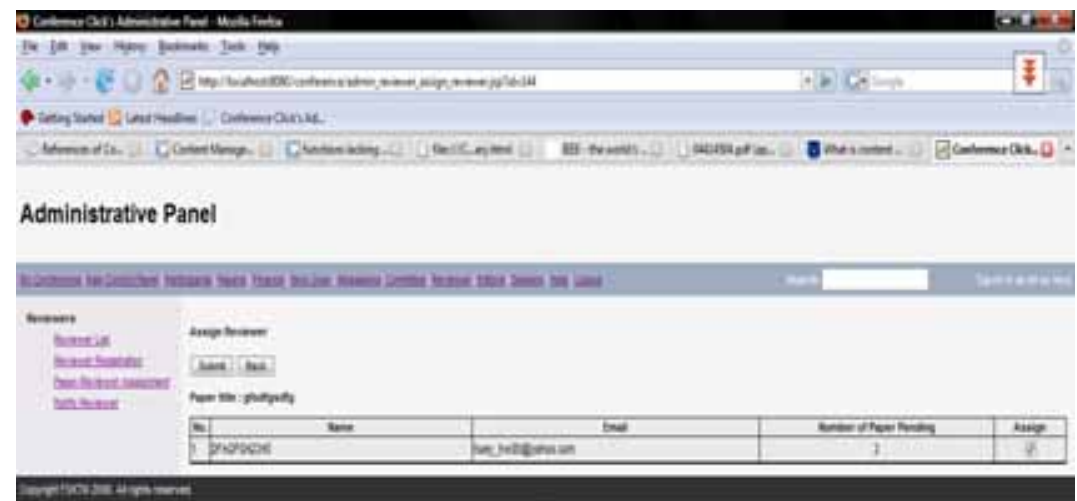



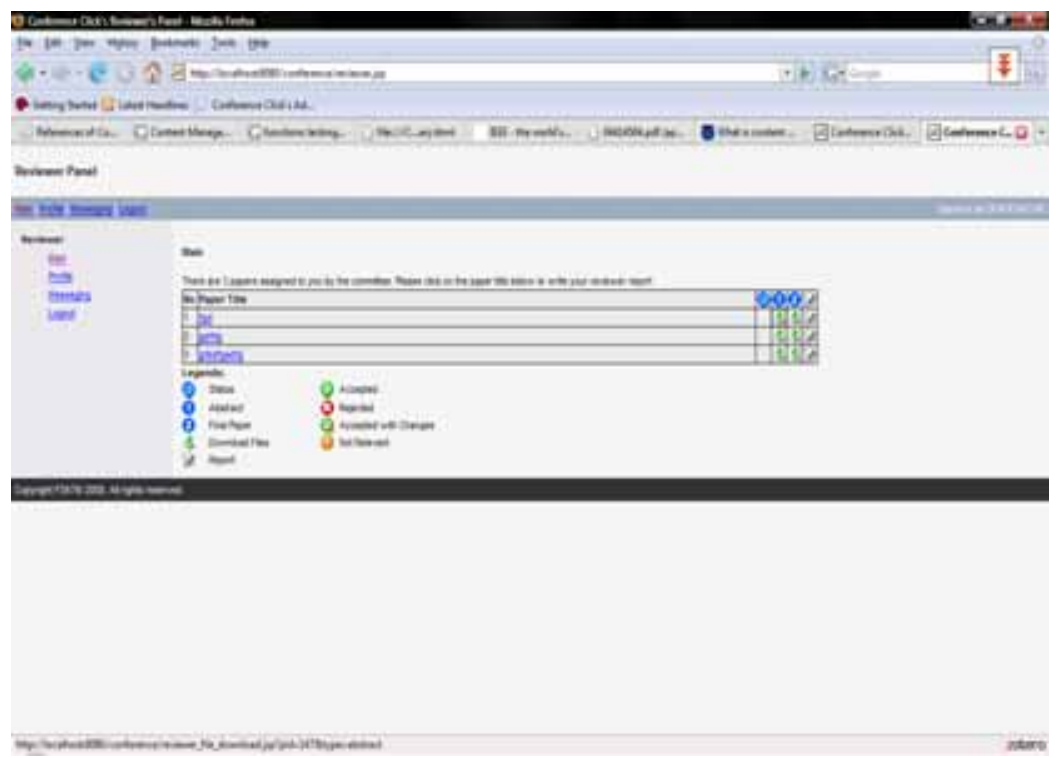

Figure 4. Screen Snapshot of Paper Reviewing Process

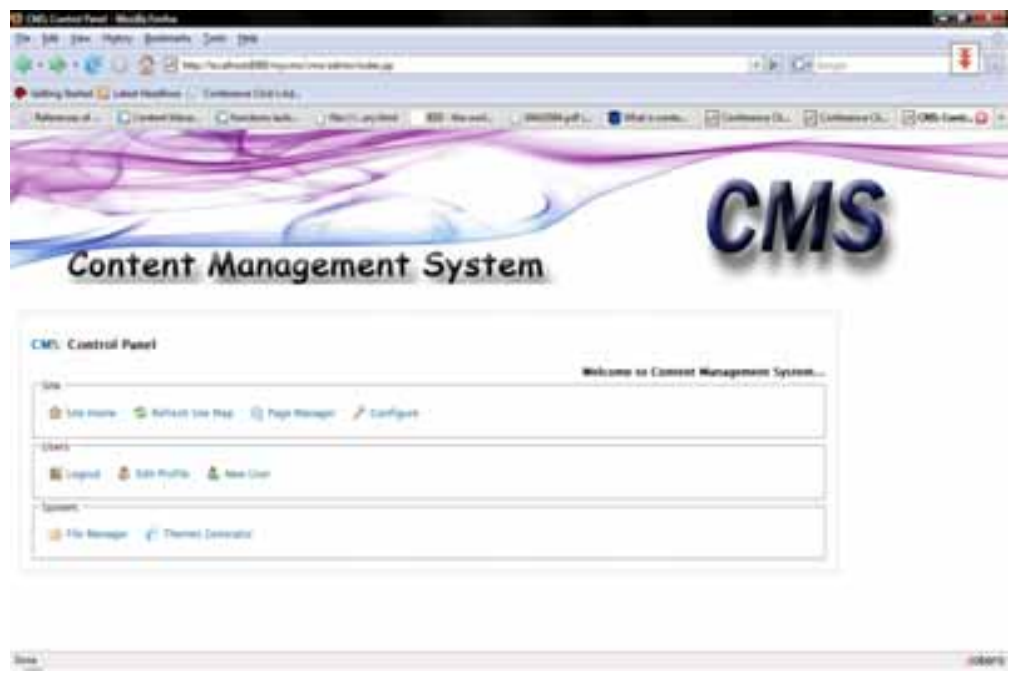

Figure 5. Screen Snapshot Customization Process 